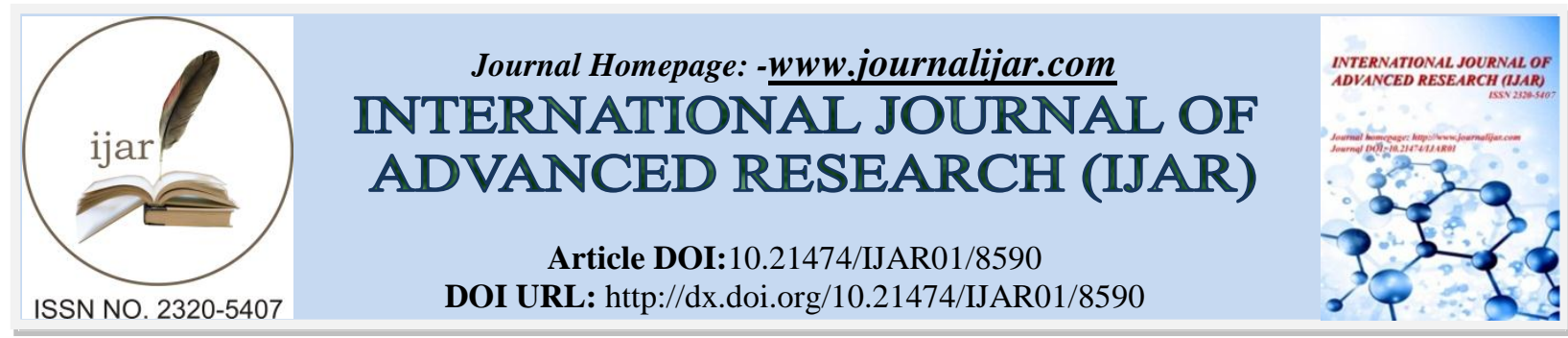

RESEARCH ARTICLE

\title{
ASSESSMENT ON SELF-CARE SKILLS OF DIABETIC CLIENTS.
}

\author{
V.Sarasvady. \\ Vinayaka Missions University, Tamil Nadu, India.
}

\section{Manuscript Info}

\section{Manuscript History}

Received: 14 December 2018

Final Accepted: 16 January 2019

Published: February 2019

\section{Key words:-}

Self-care skills, Knowledge, practice, attitude, structured interview.

\begin{abstract}
Adescriptive study aimed to assess knowledge, practice and attitude on self-care skills among diabetic clients and to teach diabetic clients on self-care skills had been conducted in the out-patient department of ESI hospital, Puducherry. Structured interview was conducted for data collection from hundred participants and were selected by using purposive sampling technique. As per the descriptive statistical findings, the conclusions drawn were as half of the participants had poor knowledge and attitude. Considerable numbers of participants had both knowledge and attitude adequately whereas majority of them had adequate practice and only minimal numbers of participants had good knowledge, practice and attitude collectivelyon self-care skills on diabetes mellitus. The inference made out of this is that diabetic patients need to be given adequate information on disease condition; complication and its management to improve their attitude to take care by themselves there by improve practicing self-care skills.
\end{abstract}

Copy Right, IJAR, 2019,. All rights reserved.

\section{Introduction:-}

Diabetes is a chronic, debilitating and costly disease associated with severe complications. Diabetes mellitus meaning 'Sweet urine' and Excess urine "Like a siphon". Diabetes mellitus is often due to Problem in insulin hormone either deficiency or inaction. Insulin is the hormone which reduces blood glucose levels, Produced by beta islets of the pancreas. Insulin is needed by body to use glucose. It sends glucose from blood to cells for use. When insulin level is decreased resulting in excess glucose in urine and blood; Pulls water through urine; Cells unable to use glucose leading to Peripheral insulin resistance in muscle and fat and increased hepatic glucose output.

The higher the blood sugar, the more sugar that sticks to red cells and the higher A1c results. An A1c measures how much sugar has been sticking to red blood cells over a 3 month period of time.
$\mathrm{HbA1c}$
Fasting
Blood glucose (3 month
Blood
2 hour after Averageglucose
$75 \mathrm{~g}$ oralGlucose)

glucose

Normal:-

$:<5.7 \%<100 \mathrm{mg} / \mathrm{dl}<140 \mathrm{mg} / \mathrm{dl}$

\author{
Diabetes:- \\ $>6.5 \%>126 \mathrm{mg} / \mathrm{dl} \quad>200 \mathrm{mg} / \mathrm{dl}$
}

Corresponding Author:- V.Sarasvady.

Address:-Vinayaka Missions University, Tamil Nadu, India. 


\section{Type1:-}

Absolute insulin deficiency; autoimmune destruction of beta islets of pancreas;affects children and younger adults $($ Age $<30)$;insulin injections needed for life; tablets do not work; less common ( $<5 \%$ of all diabetics).

\section{Type 2:-}

Most common type (> 95\% cases); usually affects adults > 40 years age; insulin deficiency - Relative; insulin resistance - insulin action inadequate; tablets work; insulin needed for control in many patients.

Other specific types of Diabetes:-

Rare $<2 \%$ of cases; pancreatic disease - chronic pancreatitis; drugs - steroids and anti-psychotics; hormonal diseases - excess steroids and excess Growth hormone; genetic diseases.

\section{Pregnancy related Diabetes:-}

Pre-existing diabetes - Type 1 or 2, newly detected during pregnancy - GDM - Gestational diabetes, occurs at 24 28 weeks gestation, usually insulin injection is the treatment of choice.

\section{Complications of Diabetes mellitus:-}

Constant high blood glucose levels cause damage to Kidneys, Nerves, Eyes, Heart and Blood vessels. Management of Diabetes mellitus Aims of treatment are maintaining normal blood glucose levels, preventing complications of diabetes, improving quality of lives of diabetics and reducing mortality and suffering. Management is multifaceted. Simple glycocentric approach is not enough. Holistic multi factorial approach is needed which includes normalize Hyper glycemia, Hypertension, Dyslipidemia, Smoking cessation, Aspirin, Body weight maintenance and Detection \& management of complications.Four pillars of hyperglycemia management

Diet/ nutrition therapy, 2. Lifestyle modification / increasing physical activity, 3.Anti-diabetic drugs, 4.Insulin. Prevention of dangers of Diabetes mellitus (Ten point formula):Early identification of Diabetes, Dietary modification, Good control of diabetes, Exercise, Control of hyper lipidemia, Weight reduction, BP control, Quit smoking, Aspirin where indicated and Relaxation techniques.

\section{Problems of diabetes:-}

India being diabetes capital of the world, diabetes is a major public health problem in India. Diabetes is more prevalent in Indians mainly type 2 diabetes. Prevalence is increasing rapidly. This may be due to younger age at onset - A decade earlier, occurs at lower BMI means thin fat Indian also affected. Proposed reasons are central obesity, rapid urbanization, more access to food and sedentary lifestyle.

Current status of diabetes in India: Increasing prevalence; Many may be undiagnosed (50\%):-

Many diagnosed may be uncontrolled (>50\%); Many likely to have complications ( $>50 \%)$. Studies from Puducherry say $16 \%$ population of above twenty years are affected by diabetes mellitus. Increasing prevalence is due to urbanization, sedentary lifestyle, less exercise, more food and obesity.

\section{Burden due to diabetes in India(Diabetic Complications):-}

Coronary Arterial Diseases:-

Urban - $21.4 \%$, Rural - $10.8 \%$.

\section{Peripheral Vascular Diseases:-}

Urban $-6.3 \%$, Rural $-7.3 \%$.

Retinopathy: Urban:-

$17.6 \%$, Rural $-18.2 \%$.

Nephropathy (Micro albuminuria): Urban - 26.9\%, Rural - 24.3\%.

Neuropathy: Urban :-

$26.1 \%$, Rural $-30.9 \%$. 


\section{Clinical Implications:-}

Diabetes in India in epidemic proportions; Huge economic burden due to diabetes \& its complications; Prevention must be emphasized by Healthy lifestyle, Healthy eating \& Physical activity.

\section{E. Non Pharmacological management (Lifestyle modification):-}

1. Physical activity: Thirty minutes brisk walking daily, Yoga etc.

2. Stress management: Stress increases blood glucose levels and weight. Stress relaxation is very helpful by means of coping skills development, family support, healthy work environment and practicing Yoga, Meditation etc.

3. Smoking cessation: Smoking causes much harm - Lung cancer - COPD - Heart disease; everyone should be advised to stop smoking.

4. Restrict Alcohol: Limit or stop alcohol intake.

5. Optimal body weight: Optimal body weight maintenance prevents diabetes. Optimal body weight is maintained by Healthy eating and Physical activity.

6. Adequate sleep:At least 8 hours sleep at night is essential to refresh the body. Good sleep keeps the body active and healthy.

7. Regular medicine intake: Regular timely medicine intake is recommended for diabetics and while taking medicines, timely food intake is essential.

8. Regular monitoring: Weight, Blood glucose levels, Cholesterol and BP.

9. Self-education and self-management skills: Healthy eating; Physical activity; Maintain optimal body weight; Glucose monitoring; Insulin injections.

10. F. Role of nurses in prevention and control of diabetes

11. Since affected persons should lead their entire life with diabetes, they need to take care by themselves. Health education allows the patients to assume responsibility and control of their own diabetes management. So nurses need to educate people about healthy living, healthy eating, healthy breakfast, physical activity and maintaining optimal weight. Nurses empower diabetic clients by teaching self-care skills and become partner with them on treatment to help providing positive results of control.

\section{Need For The Study:-}

Diabetes is certain to be one of the most common and challenging health problems in the twenty first century. According to the International Diabetic Federation (2012), India had 32 million diabetic subjects in the year of 2000, it would become 57.2 million in the year of 2025 and its number would increase to 80 million by the year 2030 .

In Puducherry state, according to health statistics 2015, the incident rate of diabetes mellitus is $21.5 / 1000$ population. This incident rate is twice high in female. The highest incidence rate is being in an age group of $35-50$ years $(38.01 / 1000)$ and above 50 years of age $(21.7 / 1000)$.

Though diabetes is a non-communicable disease, it affects the large number of people as that of communicable diseases. This may be due to adopting western life-style, alcohol consumption, smoking habits, lack of exercise and poor dietary practices.

WHO gives prime importance to non-communicable diseases especially, diabetes mellitus and introduced the theme "HALT THE RISE AND BEAT THE DIABETES" in the world health day 2016. This goal may be achieved by creating awareness regarding self-care practices of diabetic clients.

The primary concept of health is prevention of disease and promotion of health with the emphasis prevention is better than cure. In order to help diabetic clients preventing complications development due to its chronicity, the investigator planned to provide teaching program on self-care skills on diabetes mellitus. Since knowledge is the base for skill learning, investigator has done assessment of knowledge, practice and attitude on self-care of diabetic clients.

\section{Statement of the problem:-}

Assessment of knowledge, attitude and practice on self-care skills among diabetic clients.

\section{Objectives:-}

1. To assess knowledge, practice and attitude on self-care skills among diabetic clients.

2. To teach diabetic clients on self-care skills. 


\section{Methodology:-}

Research Design:-

A research design is the conceptual structure within which research is conducted. Approach of this study was quantitative and research design used was a descriptive study.

\section{Setting of the Study :-}

The study was conducted in the out-patient department of ESI hospital, Puducherry which is one of the regions of Puducherry Union Territory having ten lacks population. An average of 300 diabetic patients attends as out-patients in a regular basis in this hospital.

\section{Population:-}

As the investigator decided to do study on diabetic patients, population referred here as, 'all patients diagnosed as diabetes above 18 years of both sexes attending Government health institutions of Puducherry in out-patient department at the time of data collection'.

\section{Sample Size:-}

Sample size was100 patients with diabetes mellitus attending out-patient department of ESI hospital, Puducherry at the time of data collection.

\section{Sampling Technique:-}

Samples for this study were selected by using purposive sampling technique.

\section{Criteria for sample selection:-}

Inclusion criteria:Patients who have diabetes mellitus and regularly attend OPD of ESI hospital, Puducherry at the time of data collection, who is able to understand Tamil or English and who is willing to participate in this study.

\section{Exclusion criteria:-}

Patients with diabetes mellitus who were not willing to participate in the study.

\section{Development and description of the tools:-}

Text book of medical surgical nursing, Journals, Manuals, Reports, Articles, Published and unpublished research studies, pamphlets and newspapers were referred to prepare the tools. Tool was given a final shape with inputs from the experts. The tool consists of four sections.

\section{Section:-}

A:Demographic data of the sample. It contains 14 items related to demographic variables of the samples like age, gender, education, income, occupation, dietary pattern, food habits, family history etc. The compiled data were decrypted in table and diagram.

\section{Section - B:-}

It contains 10 items of structured questionnaire on knowledge. Knowledge refers to the pre designed, validated questions related to information on nature of diabetes and its management. Four options were given for each item and only one is the most appropriate response. The maximum score for the correct response to each item was 'one' and for the remaining three wrong responses was zero.

\section{Section - C:-}

It contains 10 items of yes or no type structured questionnaire on attitude of the subject regarding self-care management of diabetes mellitus.

\section{Section - D:-}

It contains 10 items of yes or no type structured questionnaire on practice of the subject regarding self-care management of diabetes mellitus. 


\section{H. Data collection procedure:-}

The Samples were selected as per inclusion criteria. Purpose of the study explained and informed consent taken from the samples after obtaining necessary permission from the concerned authority. The data were collected by administering a structured questionnaire by face to face interview (structured interview).

\section{Analysis And Interpretation:-}

The analyzed data had been organized and presented as

Section A:-

Distribution of samples according to demographic variables.

\section{Section B:-}

Distribution and interpretation of samples according to their knowledge, attitude and practice.

Table I:-Distribution Of Samples According To Their Age, N = 100

\begin{tabular}{|c|l|c|c|}
\hline S/No & \multicolumn{1}{|c|}{ Age of the Participants } & Frequency (n) & Percentage \\
\hline 1 & Less than 50 Years & 46 & $46 \%$ \\
\hline 2 & 51 to 65 years & 40 & $40 \%$ \\
\hline 3 & Above 65 years & 14 & $14 \%$ \\
\hline 4 & Total & 100 & $100 \%$ \\
\hline
\end{tabular}

Fig. 1:-Distribution of samples according to their age

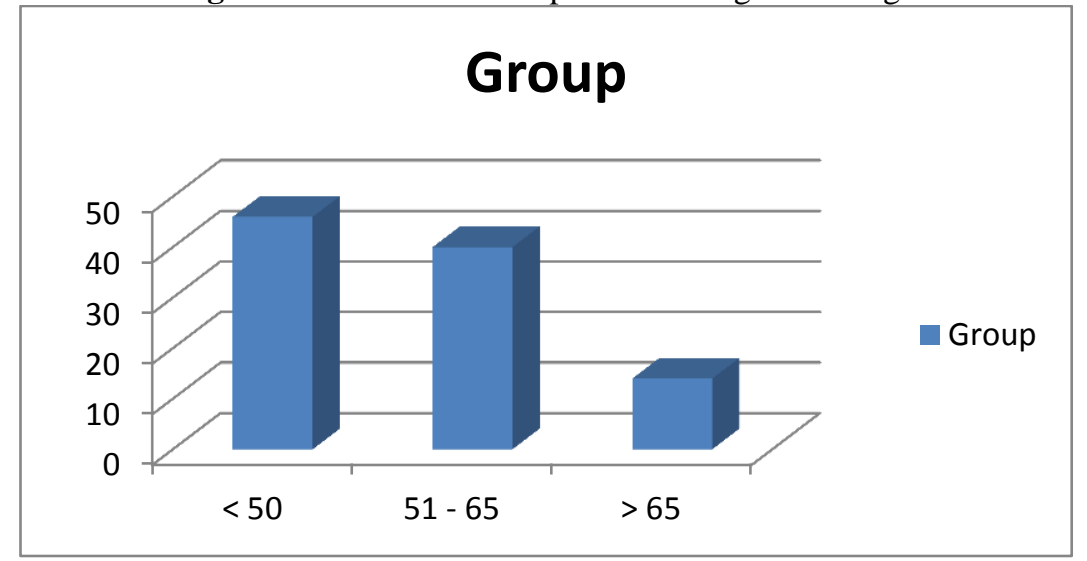

Table II:-Distribution Of Samples According To Their Gender, N = 100

\begin{tabular}{|c|l|c|c|}
\hline S/No & \multicolumn{1}{|c|}{ Gender } & Frequency (n) & Percentage \\
\hline 1 & Male & 39 & $39 \%$ \\
\hline 2 & Female & 71 & $71 \%$ \\
\hline 4 & Total & 100 & $100 \%$ \\
\hline
\end{tabular}


Fig. 2:-Distribution of samples according to their gender

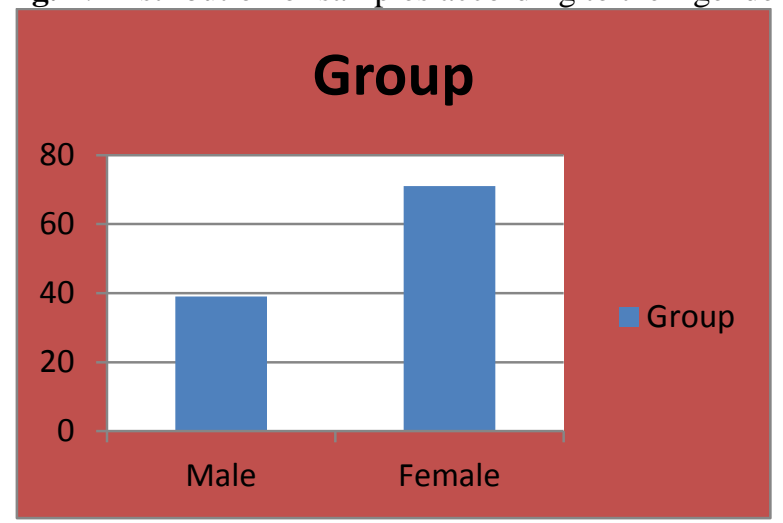

Table III:-Distribution Of Samples According To Their Educational Level, $\mathrm{N}=100$

\begin{tabular}{|c|l|c|c|}
\hline S/No & \multicolumn{1}{|c|}{ Educational level } & Frequency (n) & Percentage \\
\hline 1 & Illiterate & 26 & $26 \%$ \\
\hline 2 & School level & 63 & $63 \%$ \\
\hline 3 & College level & 11 & $11 \%$ \\
\hline 4 & Total & 100 & $100 \%$ \\
\hline
\end{tabular}

Fig. 3:-Distribution of samples according to theireducational level.

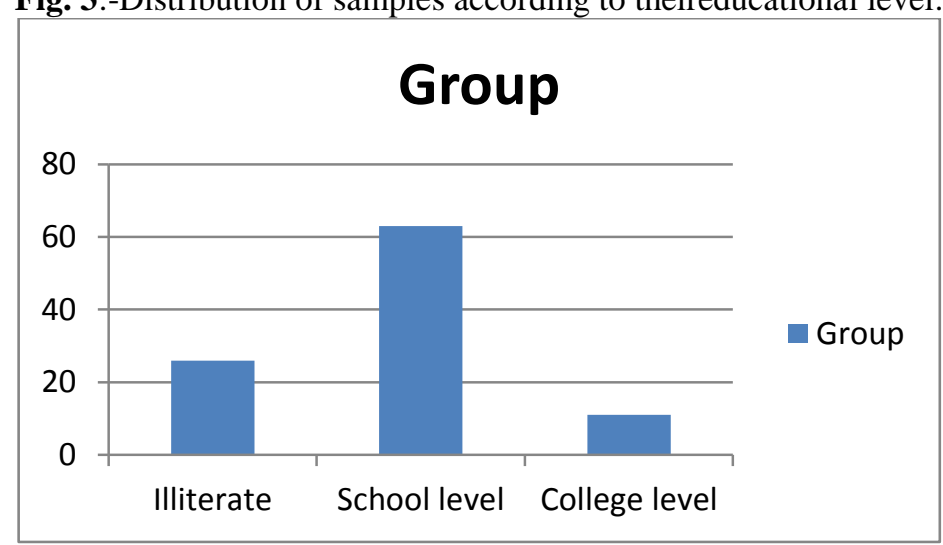

Table IV:-Distribution Of Samples According To Their Monthly Family Income, N = 100

\begin{tabular}{|c|l|c|c|}
\hline S/No & \multicolumn{1}{|c|}{ Monthly family income } & Frequency (n) & Percentage \\
\hline 1 & Less than Rs. 10000/- & 15 & $15 \%$ \\
\hline 2 & $10001 /-$ to 25000/- & 62 & $62 \%$ \\
\hline 3 & Above 25000/- & 23 & $23 \%$ \\
\hline 4 & Total & 100 & $100 \%$ \\
\hline
\end{tabular}


Fig. 4:-Distribution of samples according to their monthly family income

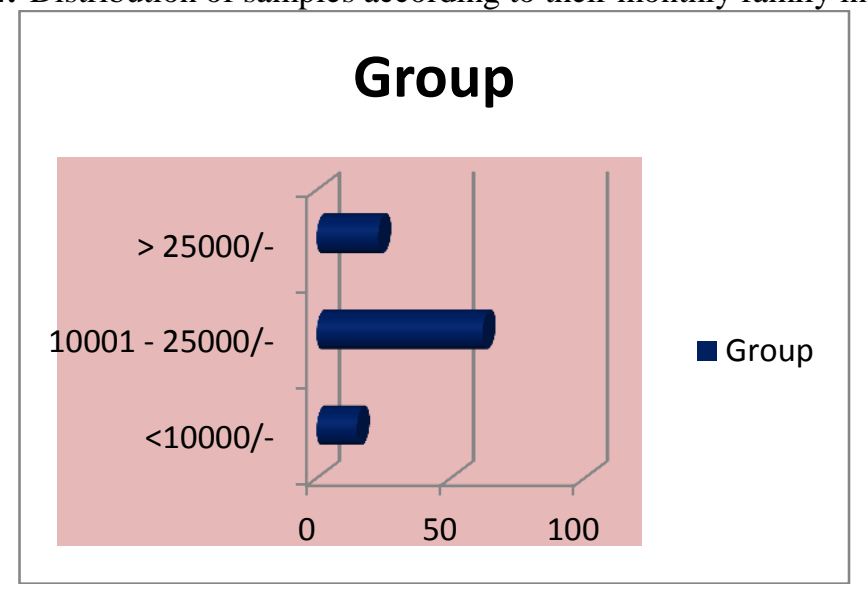

Table V:-Distribution Of Samples According To Their Work Pattern, N = 100

\begin{tabular}{|c|l|c|c|}
\hline S/No & \multicolumn{1}{|c|}{ Work pattern } & Frequency (n) & Percentage \\
\hline 1 & Sedentary worker & 53 & $53 \%$ \\
\hline 2 & Moderate worker & 38 & $38 \%$ \\
\hline 3 & Heavy worker & 09 & $09 \%$ \\
\hline 4 & Total & 100 & $100 \%$ \\
\hline
\end{tabular}

Fig. 5:-Distribution of samples according to their work pattern

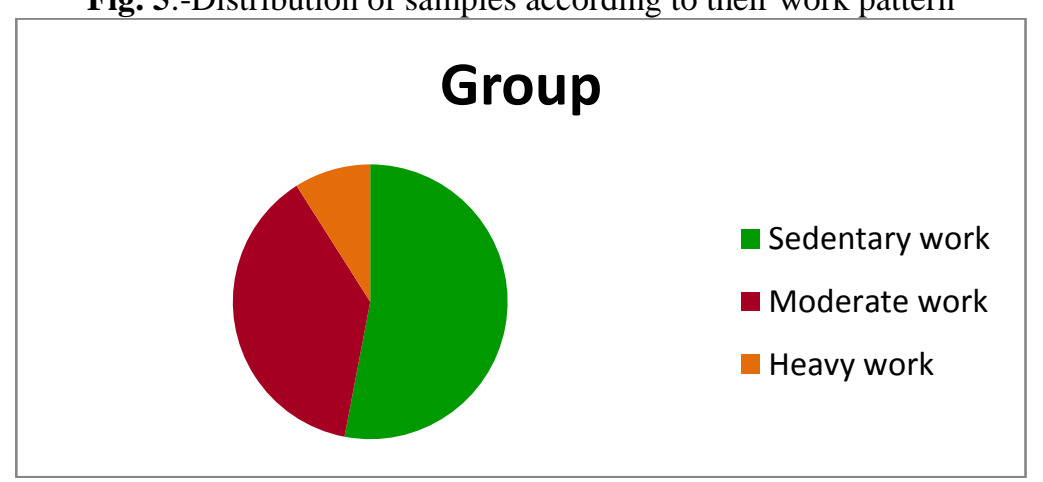

Table VI:-Distribution Of Samples According To Their Dietary Pattern, N = 100

\begin{tabular}{|c|l|c|c|}
\hline S/No & \multicolumn{1}{|c|}{ Dietary pattern } & Frequency (n) & Percentage \\
\hline 1 & Non-vegetarian & 92 & $92 \%$ \\
\hline 2 & Vegetarian & 08 & $08 \%$ \\
\hline 3 & Total & 100 & $100 \%$ \\
\hline
\end{tabular}


Fig. 6:-Distribution of samples according to their dietary pattern

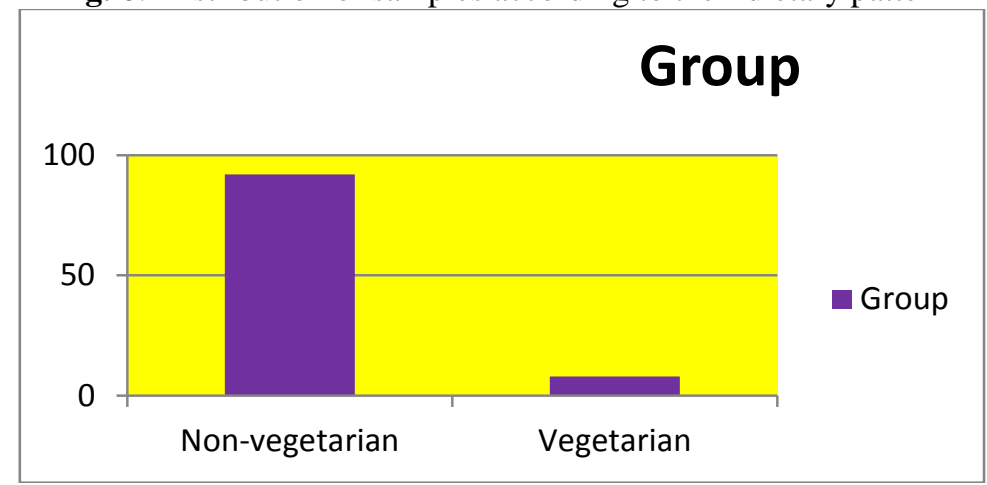

Table VII:-Distribution Of Samples According To Their Religion, $\mathrm{N}=100$

\begin{tabular}{|c|l|c|c|}
\hline S/No & \multicolumn{1}{|c|}{ Religion } & Frequency (n) & Percentage \\
\hline 1 & Hindu & 81 & $81 \%$ \\
\hline 2 & Muslim & 12 & $12 \%$ \\
\hline 3 & Christian & 07 & $07 \%$ \\
\hline 4 & Total & 100 & $100 \%$ \\
\hline
\end{tabular}

Fig. 7:-Distribution of samples according to their religion

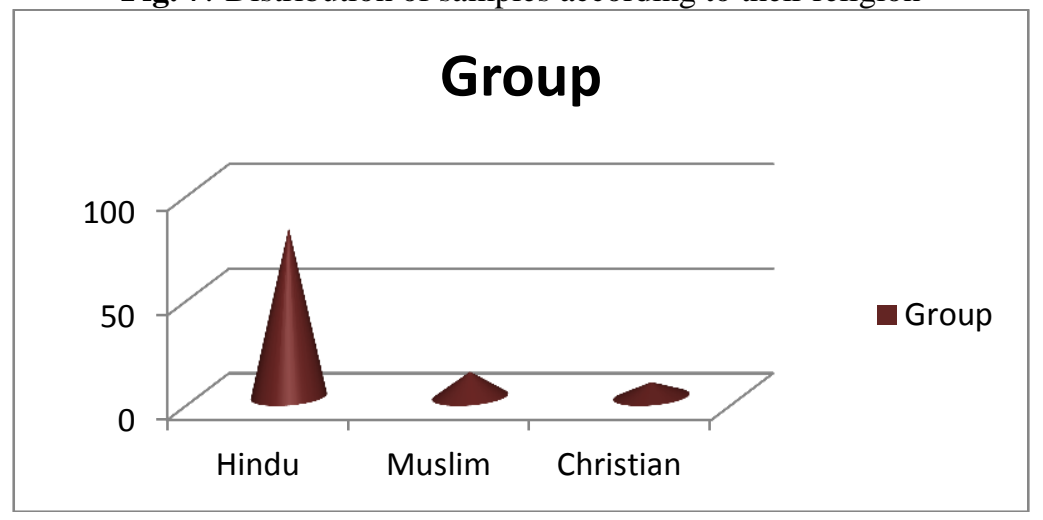

Table VIII:-DISTRIBUTION OF SAMPLES ACCORDING TO THEIR DURATION OF THE DISEASE, $\mathrm{N}=$ 100

\begin{tabular}{|c|l|c|c|}
\hline S/No & \multicolumn{1}{|c|}{ Duration of the Disease } & Frequency (n) & Percentage \\
\hline 1 & Less than 2 years & 31 & $31 \%$ \\
\hline 2 & $2-5$ years & 47 & $47 \%$ \\
\hline 3 & Above 5 years & 22 & $22 \%$ \\
\hline 4 & Total & 100 & $100 \%$ \\
\hline
\end{tabular}


Fig. 8:-Distribution of samples according to their duration of the disease

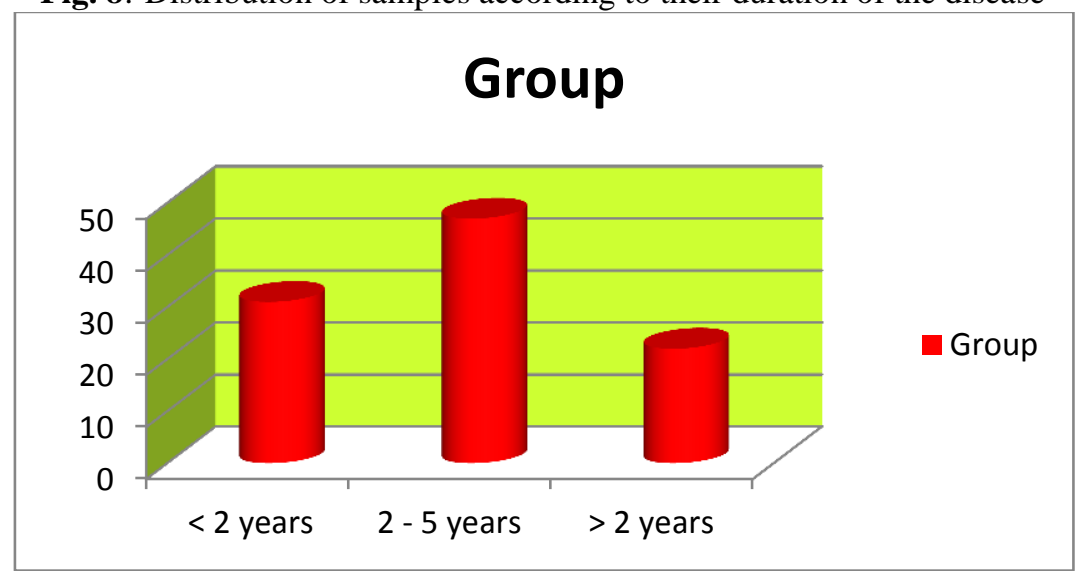

Table IX:-Distribution Of Samples According To Their Knowledge Level, N = 100

\begin{tabular}{|l|l|c|c|c|}
\hline S/No & \multicolumn{1}{|c|}{ Criteria } & Score & Frequency (n) & Percentage (\%) \\
\hline 1 & Poor & $<5$ & 50 & $50 \%$ \\
\hline 2 & Adequate & $5-7$ & 39 & $39 \%$ \\
\hline 3 & Good & $>8$ & 11 & $11 \%$ \\
\hline
\end{tabular}

Fig. 9:-Distribution of samples according to their knowledge level

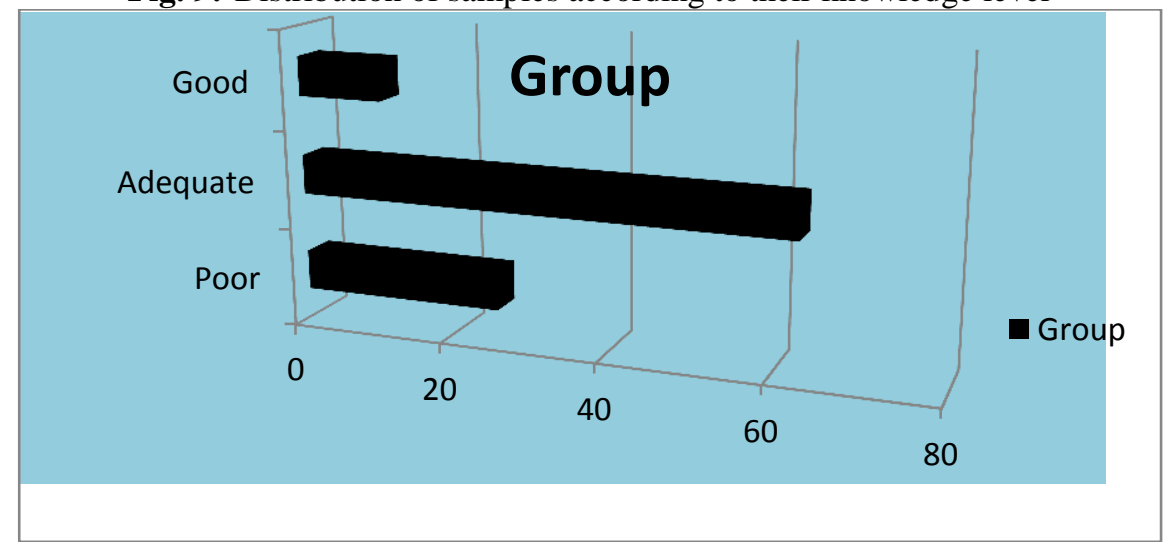

Table X:-Distribution Of Samples According To Their Practice Level, N = 100

\begin{tabular}{|l|l|c|c|c|}
\hline S/No & \multicolumn{1}{|c|}{ Criteria } & Score & Frequency (n) & Percentage (\%) \\
\hline 1 & Poor & $<5$ & 26 & $26 \%$ \\
\hline 2 & Adequate & $5-7$ & 63 & $63 \%$ \\
\hline 3 & Good & $>8$ & 11 & $11 \%$ \\
\hline
\end{tabular}


Fig. 10:-Distribution of samples according to their practice level

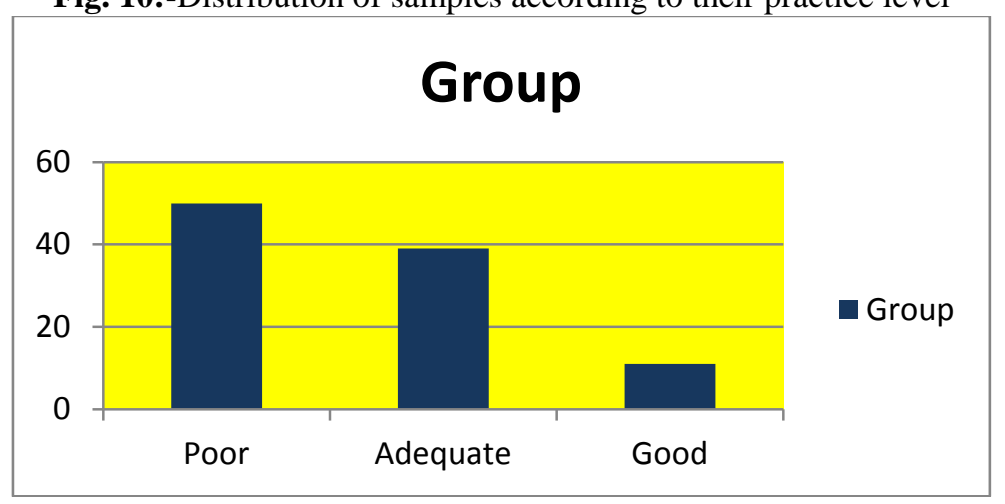

Table XI:-Distribution Of Samples According To Their Attitude Level, N = 100

\begin{tabular}{|l|l|c|c|c|}
\hline S/No & \multicolumn{1}{|c|}{ Criteria } & Score & Frequency (n) & Percentage (\%) \\
\hline 1 & Poor & $<5$ & 49 & $49 \%$ \\
\hline 2 & Adequate & $5-7$ & 47 & $47 \%$ \\
\hline 3 & Good & $>8$ & 04 & $04 \%$ \\
\hline
\end{tabular}

Fig. 11:-Distribution of samples according to their attitude level

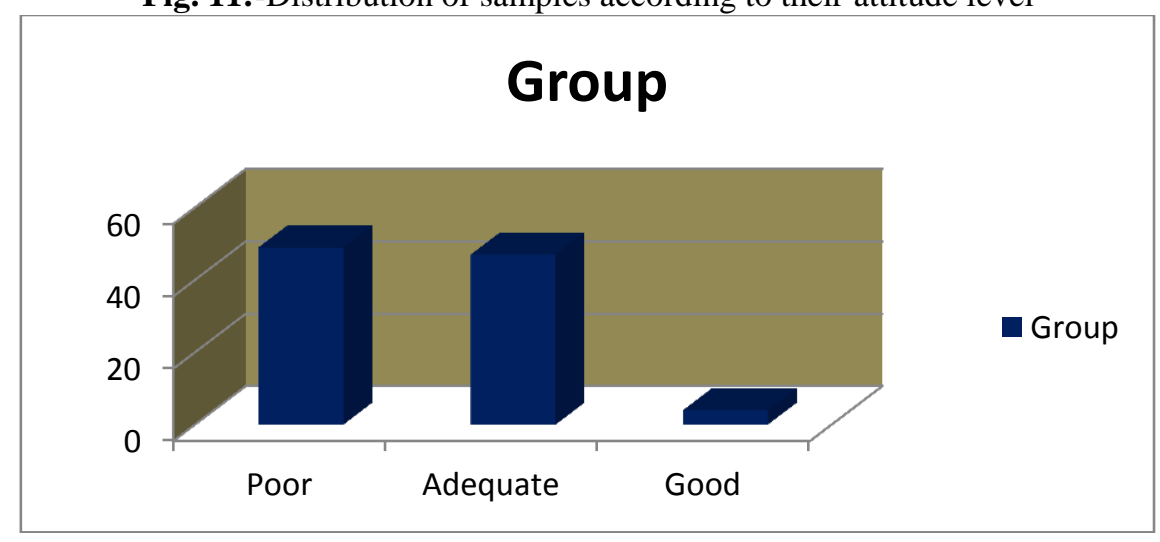

\section{Discussion:-}

On the basis of the demographic variables, out of total 100 participants, $46(46 \%)$ were less than fifty years of age, $40(40 \%)$, were between 51 and 65 years and the remaining 14 (14\%), were above 65 years of age.

According to the gender, out of total 100 participants, $39(39 \%)$ were male and 71(71\%) were female. According to the educational level, out of total 100 participants, $26(26 \%)$ were illiterate, $63(63 \%)$, were in school level and the remaining $11(11 \%)$ had college level education.

According to the monthly family income level, out of total 100 participants, 15 (15\%), were with less than Rs.10000/-, 62 (62\%) were between 10001/- to 25000/- and the remaining 23 (23\%), were with monthly family income as above $25000 /-$.

According to the work pattern, out of total 100 participants, $53(53 \%)$ were sedentary workers, 38 (38\%), were moderate workers and the remaining $9(9 \%)$, and were heavy workers. 
According to the dietary pattern, 92 (92\%), were non-vegetarian and the remaining 8 (8\%) participants were vegetarian.

According to the religion they belong, participants were categorized as Hindus (81 - 81\%), Muslims (12-12\%), and Christians $(7-7 \%)$.

According to the duration of diabetes, out of 100 participants, 31 were diagnosed with diabetes for less than two years only, 47 were between $2-5$ years of duration and the remaining 22 were with diabetes for more than 5 years.

The main objective was to assess the knowledge, attitude and practice of self care skills on diabetes mellitus. This study findings show that, out of 100 participants, 50 scored less than five (out of total ten), 39 scored between 5 and 7 and the remaining 11 scored above 8 . With the above findings, it is revealed that $50 \%$ of the diabetic clients had poor knowledge on self-care skills of diabetes mellitus. 39\% of diabetic clients had adequate knowledge on self-care skills of diabetes mellitus and the remaining $11 \%$ only had good knowledge on self-care skills of diabetes mellitus.

According to the practice, this study findings show that, out of 100 participants, 26 scored less than five out of ten, 63 scored between 5 and 7 and the remaining 11 scored above 8 . With the above findings, it is revealed that $26 \%$ of the diabetic clients had poor practice on self-care skills of diabetes mellitus. $63 \%$ of diabetic clients had adequate practice on self-care skills of diabetes mellitus and the remaining $11 \%$ only had good practice on self-care skills of diabetes mellitus.

According to the attitude, this study findings show that, out of 100 participants, 49 scored less than five out of ten, 47 scored between 5 and 7 and the remaining 4 scored above 8 . With the above findings, it is revealed that $49 \%$ of the diabetic clients had poor practice on self-care skills of diabetes mellitus. $47 \%$ of diabetic clients had adequate practice on self-care skills of diabetes mellitus and the remaining $8 \%$ only had good attitude on self-care skills of diabetes mellitus.

\section{Summary And Conclusion:- \\ Summary:-}

A descriptive study was aimed to assess knowledge, practice and attitude on self-care skills among diabetic clients and to teach diabetic clients on self-care skills. Approach of this study was quantitative. The study was conducted in the out-patient department of ESI hospital, Puducherry. Regular attendants of diabetic patients were the population; sample size was 100 and was selected by using purposive sampling technique. Data collected by structured interview.

The tool consists of four sections. Section A containsDemographic data of the sample as 14 item questionnaire. Section B contains 10 items of structured questionnaire on knowledge of diabetes mellitus. Section C contains 10 items of yes or no type structured questionnaire on attitude of the subject regarding self-care management of diabetes mellitus. Section D contains 10 items of yes or no type structured questionnaire on practice of the subject regarding self-care management of diabetes mellitus.

Descriptive statistical findings reveal that regarding knowledge, out of 100 participants, $50 \%$ of the diabetic patients had poor knowledge, $39 \%$ had adequate knowledge and $11 \%$ had good knowledge on self-care skills of diabetes mellitus. Regarding practice, out of 100 participants, $26 \%$ of the diabetic patients had poor knowledge, $63 \%$ had adequate knowledge and $11 \%$ had good practice on self-care skills of diabetes mellitus. Regarding attitude, out of 100 participants, $49 \%$ of the diabetic patients had poor knowledge, $47 \%$ had adequate knowledge and $4 \%$ had good attitude on self-care skills of diabetes mellitus.

\section{Conclusion:-}

As per these descriptive study findings on assessment of knowledge, practice and attitude on self-care skills of diabetic patients, the conclusions drawn were as half of the participants have poor knowledge and attitude. Considerable numbers of participants have adequate knowledge and attitude whereas majority of them have adequate practice and only minimal numbers of participants have good knowledge, practice and attitude on self-care skills on diabetes mellitus. 
The inference made out of this is that diabetic patients need to be given adequate information on disease condition; complication and its management to improve their attitude to take care by themselves there by improve practicing self-care skills.

\section{Acknowledgment:-}

The researcher is privileged to extend the heartfelt thanks to those who were involved in this study, especially to the participants for their highest cooperation rendered.

\section{References:-}

1. Alber Lee et al. (2011): General practice and social service partnership for better clinical outcomes, patient selfefficacy and lifestyle behaviors of diabetic care. Postgrad Med J 87, 688-693.

2. Blonde, L. et al. (2006): Interim analysis of the effects of exenatide treatment on A1C, weight and cardio vascular risk factors with type 2 diabetes. Diabetes, Obesity and Metabolism. 8(4), 436-447.

3. Camphell.Et al.: (2014): Health Promotion International. The impact of patient narratives on self-efficacy and self-care in Australians with type 2 diabetes: stage 1 results of randomized trial. 29(4).

4. Capriotti, T. (2005): Type 2 diabetes epidemic increases use of oral anti-diabetic agents. Medical Surgical Nursing, 14(5), 341-347.

5. International Diabetic Federation Atlas of Diabetes (2013), 6th edition.

6. Ishan C. Williams et al. (2014): Enhancing Diabetes Self-Care Among Rural African Americans With Diabetes. The Diabetes Educator. 40(2) 231-239.

7. Mathew Reaney et al(2014): Impact of Conversation MapTMEducation Tools Versus Regular Care on Diabetes - Related Knowlidge of People With Type 2 Diabetes: A Randomized, Controlled Study. American Association of Diabetic Education: SAGE Publication.

8. MichellGulabani. (2008): Knowledge of Diabetes, its Treatment and Complication Amongst Diabetic Patients in a Tertiary care Hospital. Indian Journal of Community Medicine., 33(3):204-206.

9. Mohan V. et al (2012), Journal of Diabetes Science and Technology 1355 - 1364.

10. Nathan, D. M. et al. 92005): Intensive diabetes treatment and cardiovascular disease in patients with type 1 diabetes. New England Journal of Medicine., 353(25), 2643-2653.

11. Porth, C.M., and Matfin, G. (2009): Pathophysiology. Concepts of altered health states., (8thed). Philadelphia: Lippincott Williams \& Wilkins.

12. Sharon A. Brown. (1990): Patient Education and Counseling. DOI. 16(3)189-215.

13. Thomas Bodenheimar M D. et al. (2002): Patient Self-management of Chronic Disease in Primary Care. JSMS.288(19), 2469-2475. 